\title{
Attenuated Psychotic Symptom Interventions in Youth at Risk of Psychosis: A Systematic Review and Meta-Analysis
}

\author{
Daniel J Devoe, MSc ${ }^{1}$, Megan Farris, MSc ${ }^{1}$, Parker Townes, BSc $^{1}$, and Jean Addington, \\ PhD ${ }^{1}$ \\ ${ }^{1}$ Department of Psychiatry, Hotchkiss Brain Institute, University of Calgary, Alberta, Canada
}

\begin{abstract}
Aim-Attenuated psychotic symptoms, APS) have been the primary emphasis in youth at clinical high risk, CHR) for psychosis for assessing symptomology and determining subsequent transition to a psychotic disorder. Previous reviews primarily focused on the efficacy of cognitive behavioral therapy, CBT) on APS, however a comprehensive assessment of other interventions to date is lacking. Therefore, we conducted a systematic review and meta-analysis of all intervention studies examining APS in CHR youth.
\end{abstract}

Method-The authors searched Embase, CINAHL, PsycINFO, Medline, and EBM from inception to May 2017. Studies were selected if they included any intervention that reported follow-up APS in youth at CHR. Interventions were evaluated and stratified by time using both pairwise and network meta-analyses, NMA). Due to the differences in APS scales, effect sizes were calculated as Hedges $g$ and reported as the standardized mean difference, SMD).

Results-Forty-one studies met our inclusion criteria. In pairwise meta-analyses, CBT was associated with a significant reduction in APS compared to controls at 18 to 24-month follow-up, SMD, $-0.22 ; 95 \% \mathrm{CI},-0.43$ to $-0.01 ; P^{2}=0 \% ; P=0.04,3$ studies, $\mathrm{N}=356$ ). In the NMA, integrated psychological therapy, CBT, supportive therapy, family therapy, needs based interventions, omega-3, risperidone plus CBT, and olanzapine were not significantly more effective at reducing APS at 6- and 12-months relative to any other intervention.

Conclusions-CBT was more effective at reducing APS at long-term follow-up compared to controls. No interventions were significantly more effective at reducing APS compared to all other interventions in the NMA.

\section{Introduction}

Attenuated psychotic symptoms, APS) have been the primary emphasis in youth at clinical high risk, CHR) of psychosis in terms of assessing current symptomology and determining criteria for being at CHR and subsequent transition to full-blown psychosis, Paolo Fusar-Poli et al., 2013; P. Fusar-Poli \& Van Os, 2013; McGlashan, Walsh, \& Woods, 2010). APS are often assessed by measures such as the Comprehensive Assessment of At-Risk Mental State, CAARMS), Alison R. Yung et al., 2005) or the Structured Interview of Psychosis-Risk

Correspondence: Dr. Jean Addington, Mathison Centre for Mental Health Research \& Education, 3280 Hospital Drive NW | Calgary, Alberta T2N 4Z6, Telephone: 403-210-6379, jmadding@ucalgary.ca. 
Syndromes, SIPS), McGlashan et al., 2010). APS typically include unusual thought content, suspiciousness, grandiosity, perceptual abnormalities, and disorganized communication. Both severity of APS and unusual thought content, disorganized communication, and suspiciousness have been shown to be predictive of transition to psychosis, Jean Addington et al., 2017; Barbara A. Cornblatt et al., 2015; Paolo Fusar-Poli et al., 2013), thus examining the impact of interventions on APS may help inform clinical guidelines and future trials. Interestingly, most treatment studies in CHR samples have focused primarily on diminishing transition rates to a psychotic disorder with the mean reduction of APS usually as a secondary aim.

To date, only two traditional pairwise meta-analyses have examined the effects of interventions on APS in CHR youth. Both reviews primarily focused on the efficacy of cognitive behavioral therapies, CBT) and found that CBT had a small effect on the reduction of APS at 12-months, P. Hutton \& Taylor, 2014; Stafford, Jackson, Mayo-Wilson, Morrison, $\&$ Kendall, 2013). However, since then, treatment studies in CHR samples have significantly increased and encompass novel interventions such as cognitive remediation therapy, CRT), glycine, D-serine, and omega-3. Our review, therefore, includes not only CBT studies but all interventions and explores their impact on APS as a primary outcome, using both traditional pairwise meta-analyses and a network analysis. Executing a network meta-analysis, NMA) allows for indirect comparisons between intervention arms in randomized controlled trials that have not previously been compared, e.g. CBT to family therapy to antipsychotics) and that use common comparators, e.g. supportive therapy or placebo). By including new interventions, more studies, and incorporating both direct and indirect evidence, the evidence base for APS interventions in CHR youth will be expanded.

\section{Method}

Protocol

We conducted this systematic review and meta-analysis according to a protocol established a priori, PROSPERO [International Prospective Register of Systematic Reviews] number: CRD42017067291) and reported in accordance with PRISMA and MOOSE guidelines, B. Hutton, Salanti, Caldwell, \& et al., 2015; Liberati et al., 2009; Moher et al., 2015; Stroup, Berlin, Morton, \& et al., 2000). PRISMA checklists are provided for both the pairwise and the NMA in Supplementary Material 1, B. Hutton, Salanti, Caldwell, Chaimani, et al., 2015; Moher, Liberati, Tetzlaff, \& Altman, 2009).

\section{Objective}

The primary objective of this systematic review and meta-analysis was to summarize and analyze the impact of all interventions on APS in youth at CHR of psychosis.

\section{Data Sources and Search Strategy}

The authors conducted database searches in PsycINFO, Medline, Embase, CINAHL, and EBM from inception to May 2017. All search details are shown in Supplementary Material 2. Each reviewer, PT and MF) autonomously completed title and abstract screening, and the full-text of any study considered appropriate according to the selection criteria was retrieved 
for a comprehensive review. In addition, a Scopus, https://www.scopus.com) search was conducted using the key words "psychosis risk" and "treatment" and both the Clinicaltrials.gov registry and The International Clinical Trials Registry Platform, http:// apps.who.int/trialsearch/) were searched using the terms "psychosis" and "risk". Lastly, reference lists of included full-text articles were hand-searched for relevant citations.

\section{Study Selection}

Two reviewers, PT and MF) independently assessed the full-text of each relevant study for inclusion. Studies that met the following eligibility criteria were selected:, 1) studies including participants at risk of psychosis meeting criteria for at-risk mental state, ARMS), attenuated psychosis symptom syndrome, APSS), or schizotypy;,2) studies including nonrandomized observational studies and RCTs;, 3) studies reporting follow-up attenuated psychotic symptom scores using either the Scale for the Assessment of Positive Symptoms, SAPS), Andreasen, 1984), Brief Psychiatric Rating Scale, BPRS), Overall \& Gorham, 1962), the Positive and Negative Syndrome Scale, PANSS), Kay, Flszbein, \& Opfer, 1987), the Scale of Prodromal Symptoms, SOPS), Miller et al., 2003), or the Comprehensive Assessment of At-Risk Mental States, CAARMS), Alison R Yung et al., 2005), and, 4) studies reporting a mean age between 12-30. Studies were not excluded based on languages. Case reports, review articles, editorials, and studies that did not employ an intervention were excluded. Differences were resolved by a third co-author, DD or JA).

\section{Data Extraction}

Two co-authors extracted all data in duplicate, PT and MF) and a third, DD) verified it. Extracted data included study characteristics, author, publication year, country, study design, CHR sample size, and attenuated psychotic symptom scales), patient characteristics, mean \pm $S D$ age, number of/percent male), and treatment characteristics, intervention, control, duration, endpoint). The following clinical outcome data were extracted from RCTs:, 1) mean $\pm S D$ APS at follow-up,, 2) mean $\pm S D$ APS changes from baseline scores to followup scores,, 3) sample size per treatment group. If articles only provided standard error or confidence intervals, a standard deviation was obtained using the Cochrane Handbook methods, J.P.T. Higgins \& Green, 2011). We obtained additional data by contacting corresponding authors, obtaining follow-up or review articles, and extracting data from graphs using GraphClick software in duplicate, Boyle, Samaha, Rodewald, \& Hoffmann, 2013).

For randomized studies risk of bias was evaluated using the Cochrane Collaboration's tool for assessing risk of bias, J.P.T. Higgins \& Green, 2011). For non-randomized studies, the Risk-Of-Bias In Non-randomized Studies of Interventions, ROBINS-I) was utilized to appraise quality of evidence, Sterne et al., 2016). In the NMA, the Grading of Recommendations Assessment, Development and Evaluation, GRADE) approach was used to evaluate the quality of evidence associated with the results in the NMA at each time point, Puhan et al., 2014). 


\section{Data Synthesis and Analysis}

Due to the differences in scales used to assess APS the principal summary measures used across the majority of meta-analyses, i.e. pairwise and network meta-analyses) were effect sizes calculated as Hedges $g$. Hedges $g$ was reported as the standardized mean difference, SMD) of APS scores at follow-up, Julian P. T. Higgins, Green, \& Scholten, 2008). However, in pairwise analysis if APS were rated on the same scale the pooled mean difference, MD) was reported instead of the SMD. D-serine and glycine, herein: NMDAR modulators) are both amino acids that serve as neuromodulators that act as coagonist on the NMDAR with glutamate, Javitt \& Zukin, 1991; Scott W. Woods et al., 2013), therefore we combined both treatments in the pairwise and the NMA. Enhanced care, treatment as usual, community care, monitoring, and needs focused interventions were coalesced as needs based interventions in meta-analyses due to similarities in design. Due to expected differences between studies due to study design, dose, CHR criteria, and the idiosyncratic treatment strategies, all results were combined using random-effects models. Only RCTs were included in both pairwise and NMA. The kappa statistic was used to determine inter-rater reliability for title and abstract screening. All SMDs, effect sizes) with a $P<.05$ were considered significant and as a typical guide SMDs of 0.2 represented a small effect, 0.5 a medium effect, and 0.8 a large effect, Cohen, 1988).

For the primary analysis, direct treatment effects on APS from interventions were combined using a pairwise random-effects model by DerSimonian and Laird, DerSimonian \& Laird, 1986). APS was stratified by available time points, e.g. 6-months, 12-months, 18-months). Thus, the likelihood of a reduction in APS in CHR youth who received a similar intervention was compared to a control intervention. Direct treatment comparisons and risk of bias were analyzed using Review Manager 5, Collaboration, 2011). Statistical heterogeneity was calculated using the $I^{2}$ statistic with an $I^{2} \geq 50 \%$ indicating substantial heterogeneity and an $I^{2} \geq 75 \%$ indicating considerable heterogeneity with a $P<.05$ considered significant.

For the secondary analysis, treatment effects between intervention arms in RCTs were evaluated using a random-effects multivariate NMA assuming consistency and a common heterogeneity across all comparisons in the network using the generic inverse-variance method, Caldwell, Ades, \& Higgins, 2005; Dias, Sutton, Ades, \& Welton, 2013). We opted for a random effects multivariate network meta-analysis as described by White, White, 2011) and Higgins, J. Higgins et al., 2012) because it can handle more than two arms in one RCT, I. R. White, J. K. Barrett, D. Jackson, \& J. Higgins, 2012) and properly accounts for correlations between effect sizes from multi-arms in RCTs. Arms in RCTs that were observational in nature, e.g., monitoring) was excluded from the NMA and studies including additional participants other than CHR were excluded from the NMA, e.g., schizotypy). The formulae for Hedges' $g$ detailed by White and Thomas 2005, White \& Thomas, 2005) was used to calculate the SMD for the NMA, which is considered an unbiased estimator and involves corrections for small numbers of degrees of freedom. APS was stratified by available time points, i.e., 6-months and 12-months). Transitivity is an important assumption in a network meta-analysis, which assumes that comparisons in the network model are consistent, Cipriani, Higgins, Geddes, \& Salanti, 2013; Jansen \& Naci, 2013; Salanti, 2012). Therefore, both a global test for inconsistency, I. R. White, J. K. Barrett, D. Jackson, \& J. P. 
Higgins, 2012) and inconsistency plots assuming loop-specific heterogeneity were produced to determine if inconsistency existed in the NMA, Chaimani, Higgins, Mavridis, Spyridonos, \& Salanti, 2013; Dias, Welton, et al., 2013; Song, Altman, Glenny, \& Deeks, 2003; Veroniki, Vasiliadis, Higgins, \& Salanti, 2013). In addition, baseline characteristics, age, CHR criteria, percent male) that might modify the treatment effect were restricted using an a priori inclusion criteria to prevent inconsistencies from being introduced into the model. Surface under the cumulative ranking curve, SUCRA) plots were inspected to establish the most effective interventions compared to a better hypothetical treatment, the quicker the curve advances to one, the more probable it will be more effective, Chaimani et al., 2013; Salanti, 2012). Network comparison-adjusted funnel plots, Chaimani et al., 2013) were used to evaluate publication bias by arrangement of interventions as active treatment vs controls. Data in the network meta-analysis were analyzed using Stata, version 13.1, StataCorp LP). The graphical toolset in Stata called "networkplot" was utilized to generate graphical illustrations of the network evidence, Chaimani et al., 2013).

\section{Results}

\section{Search Yield}

The search produced 3,164 citations after duplicates; 2,995 citations were excluded after reviewing title and abstract. Study eligibility agreement between reviewers for abstract and title screening was high, $x=0.86)$. A total of 170 articles were retrieved for full-text review. Of these, 41 primary studies were eligible for inclusion in our systematic review, 17 were included in pairwise meta-analyses and 13 were included in the NMA. See Figure 1 for reasons for exclusion.

\section{Study and Participant Characteristics}

Characteristics of the 41 studies included in the systematic review are outlined in Table 1. Of the 41 studies, 19 studies were conducted in North America, 11 in Europe, four in Australia, six in Asia, and one multi-national study. Twenty-four studies measured APS with the SOPS, PANSS, $N=11$ ), SAPS, $N=3$ ), BPRS, $\mathrm{N}=4$ ), and the CAARMS, $N=4$ ). The number of CHR participants ranged from 6 to 304, for a total of 3,146 CHR participants. The mean age was 19.6 years, $\mathrm{SD}=2.98$ ) and $1,680,53.4 \%$ ) were male, range $=28-75 \%$ ).

\section{Features of Treatment Interventions and Controls}

The mean treatment duration was 30.0 weeks, range $=4-104$ wks.). Interventions included: cognitive remediation therapy, $N=6$ ), Choi et al., 2016; Hooker et al., 2014; Loewy et al., 2016; Piskulic, Barbato, \& Addington, 2012; Rauchensteiner et al., 2011; Urben, Pihet, Jaugey, Halfon, \& Holzer, 2012), family-based treatments, $N=5$ ), Grano et al., 2016; Landa et al., 2016; McFarlane et al., 2015; Miklowitz Dj, 2014; O’Brien et al., 2007), CBT, $N=6$ ), J. Addington et al.; Kim et al., 2011; Morrison Ap, 2004; Morrison et al., 2012; Stain et al., 2016; van der Gaag et al., 2012), aripiprazole, $N=3$ ), Kobayashi et al., 2009; Liu et al., 2013; S. W. Woods et al., 2007), NMDAR modulators, $N=3$ ), Kantrowitz et al., 2016; S. W. Woods et al.), omega-3, $N=3$ ), Amminger et al.; Cadenhead et al., 2017; Patrick D. McGorry et al., 2017), integrated psychological intervention, $N=3$ ), Albert et al., 2016; Nordentoft et al., 2006; Wessels et al., 2015), risperidone plus CBT, $N=2$ ), McGorry Pd, 2013; P. D. McGorry 
et al., 2002), amisulpride, $N=1$ ), Ruhrmann et al., 2007), olanzapine, $N=1$ ), McGlashan Th, 2006), low-dose lithium, $N=1$ ), Berger et al., 2012), ziprasidone, $N=1$ ), S. Woods et al., 2017), perospirone, $N=1$ ), Tsujino et al., 2013), second generation anti-psychotics, $N=1$ ), Cornblatt et al., 2007), antipsychotics not specified, $N=3$ )(Morita et al., 2014; Shim et al., 2008; Walker et al., 2009), and heart rate variability biofeedback training, $N=1$ ), McAusland $\&$ Addington, 2016). The control conditions varied as well; placebo, $N=8$ ), computer games, $N=4$ ), needs based interventions, $N=12$ ), supportive therapy, $N=3$ ), and enhanced care, $N=1$ ). Thirteen studies did not use a control group.

\section{Risk-of-Bias Assessment}

Quality assessment of RCTs, $N=23$ ) is reported in Figure 2. All RCTs had a low risk of bias for random sequence generation, $N=23$ ). RCTs had low risk of bias for allocation concealment, 56\%) and selective reporting, 75\%). Studies had a higher risk of bias for attrition bias, $N=9$ ) and other biases such as pharmaceutical funding, $N=6$ ). Blinding of participants and personnel had the highest risk of bias, $N=10$ ). Quality assessment of observational studies using ROBINS-I and the quality of the NMA using GRADE are reported in Supplementary Material 3.

\section{Network Pattern and Network Plot}

The network formed complex star-shaped network plots at both 6 and 12-months due to having many competing interventions. In addition, the network plots had some sparse connections, e.g., integrated psychological therapy and family therapy). Placebo and needs based interventions were the most common comparators, Figure 3).

\section{Consistency and Publication Bias}

Visual inspection of the comparison-adjusted funnel plots at 6- and 12-month follow-up for symmetry demonstrated the absence of small study effects with most observations falling on the null line, Supplementary Material 4). Global tests of inconsistency and inconsistency plots found no statistically significant evidence of inconsistency in the NMA, Supplementary Material 4).

\section{Primary and Secondary Outcomes of Meta-analyses}

Psychosocial Interventions-In the pairwise analyses, CBT interventions were not associated with a significant reduction in APS compared to controls at 6 and 12 months, SMD,$-0.08 ; 95 \%$ CI, -0.26 to $0.10 ; I^{2}=0 \% ; P=0.37,5$ studies, $\mathrm{N}=499$ vs SMD,$-0.15 ; 95 \%$ CI, -0.33 to $0.02 ; P^{2}=0 \% ; P=0.09,6$ studies, $\mathrm{N}=500$; Supplementary Material 5). However, CBT was associated with a significant reduction in APS compared to controls at 18 to 24month follow-up, SMD, $-0.22 ; 95 \% \mathrm{CI},-0.43$ to $-0.01 ; P^{2}=0 \% ; P=0.04,3$ studies, $\mathrm{N}=356$ ). In the 6 and 12-month NMA, CBT interventions were not significantly more effective at reducing APS compared to any other intervention, Figure 4). At 12-months, SUCRA plots of the absolute effects and rank test among the 7 treatments indicated that CBT ranked higher than the other 6 treatments but this is in the context of no statistically supported efficacy compared to other interventions, see Supplementary Material 4). 
In the NMA family therapy was not significantly more effective at reducing APS compared to all other interventions at 6-months. At 6-months, SUCRA plots of the absolute effects and rank test among the 6 treatments indicated that family therapy ranked higher than the other 5 treatments but this is in the context of no statistically supported efficacy compared to other interventions, see Supplementary Material 4). In the NMA, IPT was not significantly more effective at reducing APS compared to any other intervention at 12-months.

Antipsychotics-In the pairwise analyses, risperidone plus CBT interventions were not associated with a significant reduction in APS at 6 or 12-month follow-up, MD, $0.39 ; 95 \%$ CI, -0.93 to $1.71 ; P^{2}=46 \% ; P=0.56,2$ studies, $\mathrm{N}=146$ vs $\mathrm{MD}, 0.19 ; 95 \% \mathrm{CI},-0.92$ to 1.31 ; $P^{2}=0 \% ; P=0.73,2$ studies, $\mathrm{N}=110$; Supplementary Material 5). In the 6-month and 12-month NMA, risperidone plus CBT interventions were not significantly more effective at reducing APS compared to any other intervention. Amisulpride and ziprasidone could not be analyzed in pairwise analyses or the NMA. Olanzapine could only be analyzed in the 12-month NMA and was not significantly more effective at reducing APS compared to any other intervention.

NMDAR modulators-In the pairwise analyses, NMDAR modulator interventions were not associated with a significant reduction in APS compared to placebo, MD, $-1.19 ; 95 \%$ CI, -4.19 to $1.80 ; I^{2}=0 \% ; P=0.43,2$ studies, $\mathrm{N}=43$; Supplementary Material 5). No NMDAR modulator studies were evaluated in the NMA due to having no comparable time-point, e.g., 6- or 12-months).

Omega-3-In the pairwise analyses, omega-3 interventions were not associated with a significant reduction in APS at 3-, 6-, or 12-month follow-up compared to placebo, SMD, $-0.23 ; 95 \% \mathrm{CI},-0.60$ to $0.14 ; P^{2}=26 \% ; P=0.23,2$ studies, $\mathrm{N}=153$ vs $\mathrm{SMD},-0.34 ; 95 \% \mathrm{CI}$, -0.97 to $0.29 ; I^{2}=87 \% ; P=0.30,3$ studies, $\mathrm{N}=389$ vs SMD, $-0.31 ; 95 \% \mathrm{CI},-0.87$ to 0.26 ; $I^{2}=81 \%, P=0.30,3$ studies, $\mathrm{N}=347$; Supplementary Material 5). In the 6- and 12-month NMA, omega-3 was not significantly more effective at reducing APS compared to any other intervention.

Cognitive remediation therapy-In the pairwise analyses, CRT interventions were not associated with a significant reduction in APS compared to computer games, MD, 1.60; $95 \%$ CI, -0.11 to $3.30 ; P^{2}=0 \% ; P=0.07,3$ studies, $\mathrm{N}=170$; Supplementary Material 5). No CRT studies were not assessed in the NMA because it was not connected to any treatment in the network.

Integrated Treatment in Schizotypy-In the pairwise analyses, integrated treatments were not associated with a significant reduction in APS compared to standard care at longterm follow-up, 2-3.5 years) in studies that targeted schizotypy participants only, MD, $-0.29 ; 95 \%$ CI, -0.72 to $0.14 ; P^{2}=0 \% ; P=0.18,2$ studies, $N=116$; Supplementary Material 5). Schizotypy studies were not assessed in the NMA because it would violate the transitivity assumption. 


\section{Discussion}

In summary, this systematic review compared the effects of CBT, family therapy, integrated psychological therapy, risperidone plus CBT, olanzapine, omega-3, and NMDAR modulators on reducing APS in CHR populations using both pairwise and network metaanalyses. First, pairwise meta-analyses revealed that CBT was associated with a significant reduction in APS compared to control treatments 18 to 24-month follow-up, based on $\mathrm{n}=356$ ), with a trend towards significance at 12-month follow-up, based on $\mathrm{n}=500$ ).

Risperidone plus CBT, NMDAR modulators, omega-3, and integrated treatments were not significantly better than controls in pairwise analyses.

In the NMA there were no significant results at both 6- and 12-months with all confidence intervals crossing the null line. However, there were some trends and effect sizes that may be of interest. First, there was a trend favoring family therapy over the majority of interventions at both 6-month follow-up and a trend favoring CBT at 12-months, compared to most other treatments.

CBT demonstrated a statistically significant benefit over controls at reducing APS at 18-24 month follow-up. This is contrary to a previous meta-analysis which reported that CBT reduced APS at 12 months but not at 6 months or long-term follow-up, P. Hutton \& Taylor, 2014). However, in the current review we did find a trend towards a significant reduction in APS at 12 months. This discrepancy in significance between reviews may be due to the presence of two additional CBT studies; one which demonstrated no impact on APS compared to controls, Stain et al., 2016), and the other which demonstrated at long term follow-up a large effect at reducing APS, Morrison et al., 2012). Regardless, both this and the previous reviews demonstrated similar effect sizes for CBT. Finally, there was a trend favoring CBT relative to other treatments at reducing APS in the 12-month NMA, albeit it was not significant.

Next, there was a trend favoring family therapy relative to other treatments at reducing APS in the NMA at 6-months, albeit it was not significant. Unfortunately, there was only one RCT examining family therapy in CHR youth and thus, the results of the NMA should be interpreted with caution until larger RCTs investigating the impact of family therapy in CHR samples emerge. However, three observational studies in CHR samples have examined the impact of family therapy on APS in CHR samples all of which have found favorable results for family therapy, Landa et al., 2016; McFarlane et al., 2015; O'Brien et al., 2007). In addition, family interventions in patients with schizophrenia have a well-established effectiveness at reducing positive symptoms and are recommended by several international clinical guidelines, Caqueo-Urízar, Rus-Calafell, Urzúa, Escudero, \& Gutiérrez-Maldonado, 2015). A recent meta-analysis in early psychosis samples demonstrated that family interventions significantly decreased both relapse and readmission rates, Bird et al., 2010).

\section{Strengths and limitations}

This review included 41 interventions with more than 3,100 CHR youth. We searched multiple electronic databases, hand searched references to identify interventions, reviewed studies and extracted data in duplicate, published our protocol a priori, and followed 
PRISMA and MOOSE guidelines. Thus, making this review the most comprehensive systematic review and largest meta-analysis of APS interventions in CHR to date. However, our study has important limitations to consider.

First, there is a lack of high-quality studies that examine interventions in CHR and the impact these interventions have on APS. Almost half of the RCTs failed to blind assessors from their respective treatment groups. Indeed, a lack of blinding of outcome assessments may have introduced important biases such as detection biases and performance biases which may have inflated the effect on APS in RCTs that failed to blind assessors, Julian P T Higgins et al., 2011).

Second, we pooled a variety of APS scales using the SMD which may have important implications when interpreting the current results. The majority of studies employed the SOPS scale for measuring APS which includes unusual thought content, suspiciousness, grandiosity, perceptual abnormalities, and disorganized communication. However, the PANSS was the second most commonly reported measure of APS which includes two additional positive symptoms, i.e., excitement and hostility) and was developed to measure psychotic symptoms in patients with schizophrenia. Interestingly, although a consensus for negative symptoms exists no consensus has emerged for positive symptoms in schizophrenia, Kirkpatrick, Fenton, Carpenter, \& Marder, 2006). Thus, future considerations should be given to the strengths and weaknesses of available instruments for measuring APS and a collective agreement of what constitutes APS in CHR should be explored by CHR researchers.

Third, there was only one closed loop of evidence at both 6- and 12-month thus inconsistency can only statistically be examined between the nodes in these loops. A global test for inconsistency at 6- and 12-month revealed no significant evidence of inconsistency. Other contributions of inconsistency were further examined using GRADE.

Fourth, another issue that arises from this NMA is that consistency of the indirect evidence cannot be adequately checked against direct evidence, especially given the limited amount of trials included in this NMA. Even though we found nothing statistically significant in terms of inconsistency in this NMA these results should be interpreted with great caution because there is a limited amount of data. Moreover, this NMA formed a complex star-shaped network and had many sparse connections, which elucidates the lack of direct evidence available in CHR studies. Indeed, the emergence of more trials in the future may change the results of this NMA entirely.

Fifth, in this NMA several estimates have been based on little data and without direct evidence. Moreover, there were many large confidence intervals as can be seen in the NMA forest plots and thus the results may be based more on interference than on the actual impact of any particular intervention. Due to this lack of precision the results should be interpreted cautiously. In addition, a lack of direct comparisons in a star-shaped network coupled with a limited amount trials could have inflated the chances of a type 2 error, which in this case may have led to the false-negative conclusion that a particular type of intervention had no effect. Indeed, as more trials emerge a single new trial could ultimately alter all of the results 
and conclusions made in this NMA. Thus, one should interpret the results of the NMA with great caution.

Sixth, risperidone plus CBT and omega-3 pairwise meta-analyses exhibited significant amounts of heterogeneity, but in meta-analyses of very few studies the $I^{2}$ statistic may not be accurate, von Hippel, 2015).

\section{Directions for future research}

The findings of the current systematic review and meta-analysis may inform several areas for future research. First, further RCTs are needed to explore the effect of family therapy. Such investigations may want to consider age of the young person, impact of expressed emotion, O'Brien et al., 2006), and implementation, Caqueo-Urízar et al., 2015). Moreover, future studies should investigate what specific components of family therapy are more effective at reducing APS, e.g. family involvement, stress management, communication training) compared to a treatment that is matched in time and clinician exposure. Finally, future CBT trials may need to consider optimal dose of treatment, and timing of intervention.

\section{Conclusions}

In conclusion, CBT was more effective at reducing APS at long-term follow-up compared to controls in pairwise analyses. No interventions were significantly more effective at reducing APS compared to all other interventions in the NMA. Family therapy although promising, require more clinical trials to determine a more precise and generalizable effect in CHR youth.

\section{Supplementary Material}

Refer to Web version on PubMed Central for supplementary material.

\section{Acknowledgments}

Funding: This work was supported by NIH grant RO1MH105178 awarded to Dr. Jean Addington and the Alberta Innovates Graduate Studentship awarded to Daniel Devoe.

The authors would like to thank librarian Helen L. Robertson for her help with conducting the electronic database search for this review.

\section{References}

Addington J, Epstein I, Liu L, French P, Boydell KM, Zipursky RB. A randomized controlled trial of cognitive behavioral therapy for individuals at clinical high risk of psychosis. Schizophrenia Research (of Publication: January 2011). 125(121):154-161.2011;

Addington J, Liu L, Perkins DO, Carrion RE, Keefe RSE, Woods SW. 2017; The Role of Cognition and Social Functioning as Predictors in the Transition to Psychosis for Youth With Attenuated Psychotic Symptoms. Schizophrenia Bulletin. 43(1):57-63. DOI: 10.1093/schbul/sbw152 [PubMed: 27798225]

Albert N, Glenthøj LB, Melau M, Jensen H, Hjorthøj C, Nordentoft M. 2016; Course of illness in a sample of patients diagnosed with a schizotypal disorder and treated in a specialized early intervention setting. Findings from the 3.5 year follow-up of the OPUS II study. Schizophrenia Research. 182:24-30. DOI: 10.1016/j.schres.2016.10.013 [PubMed: 27760701] 
Amminger GP, Schafer MR, Papageorgiou K, Klier CM, Cotton SM, Harrigan MSM, ... Berger GE. Long-chain omega-3 fatty acids for indicated prevention of psychotic disorders: A randomized, placebo-controlled trial. Archives of General Psychiatry (of Publication: February 2010). 67(62): 146-154.2010;

Andreasen NC. 1984; Scale for the assessment of positive symptoms. Group. 17(2):173-180.

Cornblatt, Barbara A; Carrión, Ricardo E; Auther, Andrea; McLaughlin, Danielle; Olsen, Ruth H; John, Majnu; Correll, Christoph U. 2015; Psychosis Prevention: A Modified Clinical High Risk Perspective From the Recognition and Prevention, RAP) Program. American Journal of Psychiatry. 172(10):986-994. DOI: 10.1176/appi.ajp.2015.13121686 [PubMed: 26046336]

Berger GE, Wood SJ, Ross M, Hamer CA, Wellard RM, Pell G, ... McGorry PD. 2012; Neuroprotective effects of low-dose lithium in individuals at ultra-high risk for psychosis. A longitudinal MRI/MRS study. Curr Pharm Des. 18(4):570-575. [PubMed: 22239590]

Bird V, Premkumar P, Kendall T, Whittington C, Mitchell J, Kuipers E. 2010; Early intervention services, cognitive-behavioural therapy and family intervention in early psychosis: systematic review. The British Journal of Psychiatry. 197(5):350-356. DOI: 10.1192/bjp.bp.109.074526 [PubMed: 21037211]

Boyle MA, Samaha AL, Rodewald AM, Hoffmann AN. 2013; Evaluation of the reliability and validity of GraphClick as a data extraction program. Computers in Human Behavior. 29(3):1023-1027. DOI: $10.1016 / j . c h b .2012 .07 .031$

Cadenhead K, Addington J, Cannon T, Cornblatt B, Mathalon D, McGlashan T, ... Woods S. 2017; Omega-3 Fatty Acid Versus Placebo in a Clinical High-Risk Sample From the North American Prodrome Longitudinal Studies, NAPLS) Consortium. Schizophrenia Bulletin. 43(suppl_1):S16S16. DOI: 10.1093/schbul/sbx021.042

Caldwell DM, Ades AE, Higgins JPT. 2005; Simultaneous comparison of multiple treatments: combining direct and indirect evidence. BMJ. 331(7521):897-900. DOI: 10.1136/bmj. 331.7521.897 [PubMed: 16223826]

Caqueo-Urízar A, Rus-Calafell M, Urzúa A, Escudero J, Gutiérrez-Maldonado J. 2015; The role of family therapy in the management of schizophrenia: challenges and solutions. Neuropsychiatric Disease and Treatment. 11:145-151. DOI: 10.2147/NDT.S51331 [PubMed: 25609970]

Chaimani A, Higgins JPT, Mavridis D, Spyridonos P, Salanti G. 2013; Graphical Tools for Network Meta-Analysis in STATA. PLOS ONE. 8(10):e76654.doi: 10.1371/journal.pone.0076654 [PubMed: 24098547]

Choi J, Corcoran CM, Fiszdon JM, Stevens M, Javitt DC, Deasy M, ... Pearlson GD. 2016Pupillometer-Based Neurofeedback Cognitive Training to Improve Processing Speed and Social Functioning in Individuals at Clinical High Risk for Psychosis. Psychiatric Rehabilitation Journal.

Cipriani A, Higgins JT, Geddes JR, Salanti G. 2013; COnceptual and technical challenges in network meta-analysis. Annals of Internal Medicine. 159(2):130-137. DOI: 10.7326/0003-4819-159-2-201307160-00008 [PubMed: 23856683]

Cohen, J. Statistical power analysis for the behavioral sciences. Lawrence Earlbaum Associates; Hillsdale, NJ: 1988. 20-26.

Collaboration, C. Review manager, RevMan)[computer program]: Version. 2011.

Cornblatt BA, Lencz T, Smith CW, Olsen R, Auther AM, Nakayama E, ... Correll CU. 2007; Can antidepressants be used to treat the schizophrenia prodrome? Results of a prospective, naturalistic treatment study of adolescents. Journal of Clinical Psychiatry. 68(4):546-557. [PubMed: 17474810]

DerSimonian R, Laird N. 1986; Meta-analysis in clinical trials. Controlled Clinical Trials. 7(3):177188. DOI: 10.1016/0197-2456(86)90046-2 [PubMed: 3802833]

Dias S, Sutton AJ, Ades AE, Welton NJ. 2013; Evidence Synthesis for Decision Making 2: A Generalized Linear Modeling Framework for Pairwise and Network Meta-analysis of Randomized Controlled Trials. Medical Decision Making. 33(5):607-617. DOI: 10.1177/0272989X12458724 [PubMed: 23104435] 
Dias S, Welton NJ, Sutton AJ, Caldwell DM, Lu G, Ades AE. 2013; Evidence Synthesis for Decision Making 4. Medical Decision Making. 33(5):641-656. DOI: 10.1177/0272989X12455847 [PubMed: 23804508]

Fusar-Poli P, Borgwardt S, Bechdolf A, Addington J, Riecher-Rossler A, Schultze-Lutter F, ... Yung A. 2013; The psychosis high-risk state: A comprehensive state-of-the-art review. JAMA Psychiatry. 70(1):107-120. [PubMed: 23165428]

Fusar-Poli P, Van Os J. 2013; Lost in transition: setting the psychosis threshold in prodromal research. Acta Psychiatrica Scandinavica. 127(3):248-252. DOI: 10.1111/acps.12028 [PubMed: 23136851]

Grano N, Karjalainen M, Ranta K, Lindgren M, Roine M, Therman S. 2016; Community-oriented family-based intervention superior to standard treatment in improving depression, hopelessness and functioning among adolescents with any psychosis-risk symptoms. Psychiatry Research. 237:9-16. [PubMed: 26921045]

Higgins J, Jackson D, Barrett J, Lu G, Ades A, White I. 2012; Consistency and inconsistency in network meta-analysis: concepts and models for multi-arm studies. Research synthesis methods. 3(2):98-110. [PubMed: 26062084]

Higgins JPT, Altman DG, Gøtzsche PC, Jüni P, Moher D, Oxman AD, ... Sterne JAC. 2011; The Cochrane Collaboration's tool for assessing risk of bias in randomised trials. BMJ. 343doi: 10.1136/bmj.d5928

Higgins, JPT, Green, S. Cochrane Handbook for Systematic Reviews of Interventions. Wiley; 2011.

Higgins, JPT, Green, S, Scholten, RJPM. Cochrane Handbook for Systematic Reviews of Interventions. John Wiley \& Sons, Ltd; 2008. Maintaining Reviews: Updates, Amendments and Feedback; 31-49.

Hooker CI, Carol EE, Eisenstein T, Yin H, Lincoln SH, Tully LM, ... Seidman LJ. 2014; A pilot study of cognitive training in clinical high risk for psychosis: Initial evidence of cognitive benefit. Schizophrenia Research. 157(1-3):314-316. [PubMed: 24954429]

Hutton B, Salanti G, Caldwell DM, Chaimani A, Schmid CH, Cameron C, ... Moher D. 2015; The PRISMA extension statement for reporting of systematic reviews incorporating network metaanalyses of health care interventions: checklist and explanations. Ann Intern Med. 162(11):777784. DOI: 10.7326/m14-2385 [PubMed: 26030634]

Hutton B, Salanti G, Caldwell DM, et al. 2015; The prisma extension statement for reporting of systematic reviews incorporating network meta-analyses of health care interventions: Checklist and explanations. Annals of Internal Medicine. 162(11):777-784. DOI: 10.7326/M14-2385 [PubMed: 26030634]

Hutton P, Taylor P. 2014; Cognitive behavioural therapy for psychosis prevention: A systematic review and meta-analysis. Psychological Medicine. 44(3):449-468. [PubMed: 23521867]

Jansen JP, Naci H. 2013; Is network meta-analysis as valid as standard pairwise meta-analysis? It all depends on the distribution of effect modifiers. BMC Medicine. 11(1):159.doi: 10.1186/1741-7015-11-159 [PubMed: 23826681]

Javitt DC, Zukin SR. 1991; Recent advances in the phencyclidine model of schizophrenia. Am J Psychiatry. 148(10):1301-1308. [PubMed: 1654746]

Kantrowitz JT, Woods SW, Petkova E, Cornblatt B, Corcoran CM, Chen H, ... Javitt DC. 2016; “Dserine for the treatment of negative symptoms in individuals at clinical high risk of schizophrenia: A pilot, double-blind, placebo-controlled, randomised parallel group mechanistic proof-of-concept trial": Correction. The Lancet Psychiatry. 3(7):602.

Kay SR, Flszbein A, Opfer LA. 1987; The positive and negative syndrome scale, PANSS) for schizophrenia. Schizophrenia bulletin. 13(2):261. [PubMed: 3616518]

Kim KR, Lee SY, Kang JI, Kim BR, Choi SH, Park JY, ... Kwon JS. 2011; Clinical efficacy of individual cognitive therapy in reducing psychiatric symptoms in people at ultra-high risk for psychosis. Early intervention in psychiatry. 5(2):174-178. [PubMed: 21535425]

Kirkpatrick B, Fenton WS, Carpenter JWT, Marder SR. 2006; The NIMH-MATRICS Consensus Statement on Negative Symptoms. Schizophrenia Bulletin. 32(2):214-219. DOI: 10.1093/schbul/ sbj053 [PubMed: 16481659]

Kobayashi H, Morita K, Takeshi K, Koshikawa H, Yamazawa R, Kashima H, Mizuno M. 2009; Effects of aripiprazole on insight and subjective experience in individuals with an at-risk mental state. $\mathrm{J}$ 
Clin Psychopharmacol. 29(5):421-425. DOI: 10.1097/JCP.0b013e3181b2fe22 [PubMed: 19745640]

Landa Y, Mueser KT, Wyka KE, Shreck E, Jespersen R, Jacobs MA, ... Walkup JT. 2016; Development of a group and family-based cognitive behavioural therapy program for youth at risk for psychosis. Early intervention in psychiatry. 10(6):511-521. [PubMed: 25585830]

Liberati A, Altman DG, Tetzlaff J, Mulrow C, Gotzsche PC, Ioannidis JP, ... Moher D. 2009; The PRISMA statement for reporting systematic reviews and meta-analyses of studies that evaluate healthcare interventions: explanation and elaboration. BMJ. 339:b2700.doi: 10.1136/bmj.b2700 [PubMed: 19622552]

Liu CC, Chien YL, Hsieh MH, Hwang TJ, Hwu HG, Liu CM. 2013; Aripiprazole for drug-naive or antipsychotic-short-exposure subjects with ultra-high risk state and first-episode psychosis: an open-label study. Journal of Clinical Psychopharmacology. 33(1):18-23. [PubMed: 23277261]

Loewy R, Fisher M, Schlosser DA, Biagianti B, Stuart B, Mathalon DH, Vinogradov S. 2016; Intensive Auditory Cognitive Training Improves Verbal Memory in Adolescents and Young Adults at Clinical High Risk for Psychosis. Schizophr Bull. 42(Suppl 1):S118-126. DOI: 10.1093/schbul/ sbw009 [PubMed: 26903238]

McAusland L, Addington J. 2016; Biofeedback to treat anxiety in young people at clinical high risk for developing psychosis. Early intervention in psychiatry. 29:29.

McFarlane WR, Levin B, Travis L, Lucas F, Lynch S, Verdi M, ... Spring E. 2015; Clinical and functional outcomes after 2 years in the early detection and intervention for the prevention of psychosis multisite effectiveness trial. Schizophrenia Bulletin. 41(1):30-43. [PubMed: 25065017]

McGlashan, T, Walsh, B, Woods, S. The psychosis-risk syndrome: handbook for diagnosis and followup. Oxford University Press; 2010.

McGlashan Th ZRB, Perkins D, Addington J, Miller T, Woods SW, Hawkins KA, Hoffman RE, Preda A, Epstein I, Addington D, Lindborg S, Trzaskoma Q, Tohen M, Breier A. 2006; Randomized, double-blind trial of olanzapine versus placebo in patients prodromally symptomatic for psychosis. The American journal of psychiatry. 163(5):790-799. [PubMed: 16648318]

McGorry Pd NB, Phillips LJ, Yuen HP, Francey SM, Thampi A, Berger GE, Amminger GP, Simmons MB, Kelly D, Dip G, Thompson AD, Yung AR. 2013; Randomized controlled trial of interventions for young people at ultra-high risk of psychosis: twelve-month outcome. The Journal of clinical psychiatry. 74(4):349-356. [PubMed: 23218022]

McGorry PD, Nelson B, Markulev C, Yuen HP, Schafer MR, Mossaheb N, ... Amminger G. 2017; Effect of omega-3 polyunsaturated fatty acids in young people at ultrahigh risk for psychotic disorders: The NEURAPRO randomized clinical trial. 74(1):19-27.

McGorry PD, Yung AR, Phillips LJ, Yuen HP, Francey S, Cosgrave EM, ... Jackson H. 2002; Randomized controlled trial of interventions designed to reduce the risk of progression to firstepisode psychosis in a clinical sample with subthreshold symptoms. Arch Gen Psychiatry. 59(10): 921-928. [PubMed: 12365879]

Miklowitz Dj OBMP, Schlosser DA, Addington J, Candan KA, Marshall C, Domingues I, Walsh BC, Zinberg JL, De Silva SD, Friedman-Yakoobian M, Cannon TD. 2014; Family-focused treatment for adolescents and young adults at high risk for psychosis: results of a randomized trial. Journal of the american academy of child and adolescent psychiatry. 53(8):848-858. [PubMed: 25062592]

Miller TJ, McGlashan TH, Rosen JL, Cadenhead K, Ventura J, McFarlane W, ... Woods SW. 2003; Prodromal assessment with the structured interview for prodromal syndromes and the scale of prodromal symptoms: predictive validity, interrater reliability, and training to reliability. Schizophrenia bulletin. 29(4):703. [PubMed: 14989408]

Moher D, Liberati A, Tetzlaff J, Altman DG. 2009; Preferred reporting items for systematic reviews and meta-analyses: the PRISMA statement. BMJ. 339

Moher D, Shamseer L, Clarke M, Ghersi D, Liberati A, Petticrew M, ... Stewart LA. 2015; Preferred reporting items for systematic review and meta-analysis protocols, PRISMA-P) 2015 statement. Systematic Reviews. 4(1):1.doi: 10.1186/2046-4053-4-1 [PubMed: 25554246]

Morita K, Kobayashi H, Takeshi K, Tsujino N, Nemoto T, Mizuno M. 2014; Poor outcome associated with symptomatic deterioration among help-seeking individuals at risk for psychosis: A naturalistic follow-up study. Early intervention in psychiatry. 8(1):24-31. [PubMed: 23343086] 
Morrison Ap FP, Walford L, Lewis SW, Kilcommons A, Green J, Parker S, Bentall RP. 2004; Cognitive therapy for the prevention of psychosis in people at ultra-high risk: randomised controlled trial. The British journal of psychiatry : the journal of mental science. 185:291-297. [PubMed: 15458988]

Morrison AP, French P, Stewart SLK, Birchwood M, Fowler D, Gumley AI, ... Dunn G. 2012; Early detection and intervention evaluation for people at risk of psychosis: multisite randomised controlled trial. BMJ : British Medical Journal. 344doi: 10.1136/bmj.e2233

Nordentoft M, Thorup A, Petersen L, Ohlenschlaeger J, Melau M, Christensen TO, ... Jeppesen P. 2006; Transition rates from schizotypal disorder to psychotic disorder for first-contact patients included in the OPUS trial. A randomized clinical trial of integrated treatment and standard treatment. Schizophrenia Research. 83(1):29-40. [PubMed: 16504481]

O'Brien MP, Gordon JL, Bearden CE, Lopez SR, Kopelowicz A, Cannon TD. 2006; Positive family environment predicts improvement in symptoms and social functioning among adolescents at imminent risk for onset of psychosis. Schizophrenia Research. 81(2-3):269-275. [PubMed: 16309893]

O’Brien MP, Zinberg JL, Bearden CE, Daley M, Niendam TA, Kopelowicz A, Cannon TD. 2007; Psychoeducational multi-family group treatment with adolescents at high risk for developing psychosis. 1(4):325-332.

Overall JE, Gorham DR. 1962; The brief psychiatric rating scale. Psychological reports. 10(3):799_ 812.

Piskulic D, Barbato M, Addington J. 2012; Effects of cognitive remediation on cognition in young people at clinical high risk of psychosis. Schizophrenia Research. 136:S245-S246.

Puhan MA, Schünemann HJ, Murad MH, Li T, Brignardello-Petersen R, Singh JA, ... Guyatt GH. 2014; A GRADE Working Group approach for rating the quality of treatment effect estimates from network meta-analysis. BMJ : British Medical Journal. 349doi: 10.1136/bmj.g5630

Rauchensteiner S, Kawohl W, Ozgurdal S, Littmann E, Gudlowski Y, Witthaus H, ... Juckel G. 2011; Test-performance after cognitive training in persons at risk mental state of schizophrenia and patients with schizophrenia. Psychiatry Research. 185(3):334-339. [PubMed: 20493540]

Ruhrmann S, Bechdolf A, Kuhn KU, Wagner M, Schultze-Lutter F, Janssen B, ... Klosterkotter J. 2007; Acute effects of treatment for prodromal symptoms for people putatively in a late initial prodromal state of psychosis. British Journal of Psychiatry. 191(SUPPL 51):s88-s95.

Salanti G. 2012; Indirect and mixed-treatment comparison, network, or multiple-treatments metaanalysis: many names, many benefits, many concerns for the next generation evidence synthesis tool. Research Synthesis Methods. 3(2):80-97. DOI: 10.1002/jrsm.1037 [PubMed: 26062083]

Shim G, Kang DH, Choi JS, Jung MH, Kwon SJ, Jang GE, Kwon JS. 2008; Prospective outcome of early intervention for individuals at ultra-high-risk for psychosis. Early intervention in psychiatry. 2(4):277-284. [PubMed: 21352161]

Song F, Altman DG, Glenny AM, Deeks JJ. 2003; Validity of indirect comparison for estimating efficacy of competing interventions: empirical evidence from published meta-analyses. BMJ. 326(7387):472.doi: 10.1136/bmj.326.7387.472 [PubMed: 12609941]

Stafford MR, Jackson H, Mayo-Wilson E, Morrison AP, Kendall T. 2013; Early interventions to prevent psychosis: Systematic review and meta-analysis. BMJ: British Medical Journal. 346

Stain HJ, Bucci S, Baker AL, Carr V, Emsley R, Halpin S, ... Startup M. 2016; A randomised controlled trial of cognitive behaviour therapy versus non-directive reflective listening for young people at ultra high risk of developing psychosis: The detection and evaluation of psychological therapy, DEPTh) trial. Schizophrenia Research. 176(2-3):212-219. [PubMed: 27554197]

Sterne JA, Hernán MA, Reeves BC, Savović J, Berkman ND, Viswanathan M, ... Higgins JP. 2016; ROBINS-I: a tool for assessing risk of bias in non-randomised studies of interventions. Bmj. 355doi: 10.1136/bmj.i4919

Stroup DF, Berlin JA, Morton SC, et al. 2000; Meta-analysis of observational studies in epidemiology: A proposal for reporting. JAMA. 283(15):2008-2012. DOI: 10.1001/jama.283.15.2008 [PubMed: 10789670] 
Tsujino N, Nemoto T, Morita K, Katagiri N, Ito S, Mizuno M. 2013; Long-term Efficacy and Tolerability of Perospirone for Young Help-seeking People at Clinical High Risk: a Preliminary Open Trial. Clinical Psychopharmacology \& Neuroscience. 11(3):132-136. [PubMed: 24465249]

Urben S, Pihet S, Jaugey L, Halfon O, Holzer L. 2012; A randomized controlled trial of the effectiveness of a Computer-Assisted Cognitive Remediation, CACR) program in adolescents with psychosis or at high risk of psychosis: Short term and long term outcomes. Early Intervention in Psychiatry. 6:41.doi: 10.1111/j.1751-7893.2012.00394.x

van der Gaag M, Nieman DH, Rietdijk J, Dragt S, Ising HK, Klaassen RM, ... Linszen DH. 2012; Cognitive behavioral therapy for subjects at ultrahigh risk for developing psychosis: A randomized controlled clinical trial. Schizophrenia Bulletin. 38(6):1180-1188. [PubMed: 22941746]

Veroniki AA, Vasiliadis HS, Higgins JPT, Salanti G. 2013; Evaluation of inconsistency in networks of interventions. International Journal of Epidemiology. 42(1):332-345. DOI: 10.1093/ije/dys222 [PubMed: 23508418]

von Hippel PT. 2015; The heterogeneity statistic I(2) can be biased in small meta-analyses. BMC Medical Research Methodology. 15:35.doi: 10.1186/s12874-015-0024-z [PubMed: 25880989]

Walker EF, Cornblatt BA, Addington J, Cadenhead KS, Cannon TD, McGlashan TH, ... Heinssen R. 2009; The relation of antipsychotic and antidepressant medication with baseline symptoms and symptom progression: a naturalistic study of the North American Prodrome Longitudinal Sample. Schizophrenia Research. 115(1):50-57. [PubMed: 19709859]

Wessels H, Wagner M, Frommann I, Berning J, Putzfeld V, Janssen B, ... Bechdolf A. 2015; Neuropsychological functioning as a predictor of treatment response to psychoeducational, cognitive behavioral therapy in people at clinical high risk of first episode psychosis. Psychiatrische Praxis. 42(6):313-319. [PubMed: 26308457]

White IR. 2011; Multivariate random-effects meta-regression: updates to mvmeta. Stata Journal. 11(2): 255.

White IR, Barrett JK, Jackson D, Higgins J. 2012; Consistency and inconsistency in network metaanalysis: model estimation using multivariate meta-regression. Research synthesis methods. 3(2): 111-125. [PubMed: 26062085]

White IR, Barrett JK, Jackson D, Higgins JP. 2012; Consistency and inconsistency in network metaanalysis: model estimation using multivariate meta-regression. Res Synth Methods. 3(2):111-125. DOI: 10.1002/jrsm.1045 [PubMed: 26062085]

White IR, Thomas J. 2005; Standardized mean differences in individually-randomized and clusterrandomized trials, with applications to meta-analysis. Clinical Trials. 2(2):141-151. [PubMed: 16279136]

Woods, S; Saksa, J; Compton, M; Daley, M; Rajarethinam, R; Graham, K; ... McGlashan, T. Effects of ziprasidone versus placebo in patients at clinical high risk for psychosis. Schizophrenia Bulletin, Conference (States), 16th International Congress on Schizophrenia Research; 2017.

Woods SW, Tully EM, Walsh BC, Hawkins KA, Callahan JL, Cohen SJ, ... McGlashan TH. 2007; Aripiprazole in the treatment of the psychosis prodrome: An open-label pilot study. British Journal of Psychiatry. 191(SUPPL 51):s96-s101.

Woods SW, Walsh BC, Hawkins KA, Miller TJ, Saksa JR, D’Souza DC, ... Krystal JH. Glycine treatment of the risk syndrome for psychosis: Report of two pilot studies. European Neuropsychopharmacology (of Publication: August 2013). 23(28):931-940.2013;

Woods SW, Walsh BC, Hawkins KA, Miller TJ, Saksa JR, D’Souza DC, ... Krystal JH. 2013; Glycine treatment of the risk syndrome for psychosis: Report of two pilot studies. European Neuropsychopharmacology. 23(8):931-940. [PubMed: 23089076]

Yung AR, Yuen HP, McGorry PD, Phillips LJ, Kelly D, Dell’Olio M, ... Buckby J. 2005; Mapping the onset of psychosis: the Comprehensive Assessment of At-Risk Mental States. Australian \& New Zealand Journal of Psychiatry. 39(11/12):964-971. DOI: 10.1111/j.1440-1614.2005.01714.x [PubMed: 16343296]

Yung AR, Yung AR, Pan Yuen H, Mcgorry PD, Phillips LJ, Kelly D, ... Killackey E. 2005; Mapping the onset of psychosis: the comprehensive assessment of at-risk mental states. Australian and New Zealand Journal of Psychiatry. 39(11-12):964-971. [PubMed: 16343296] 


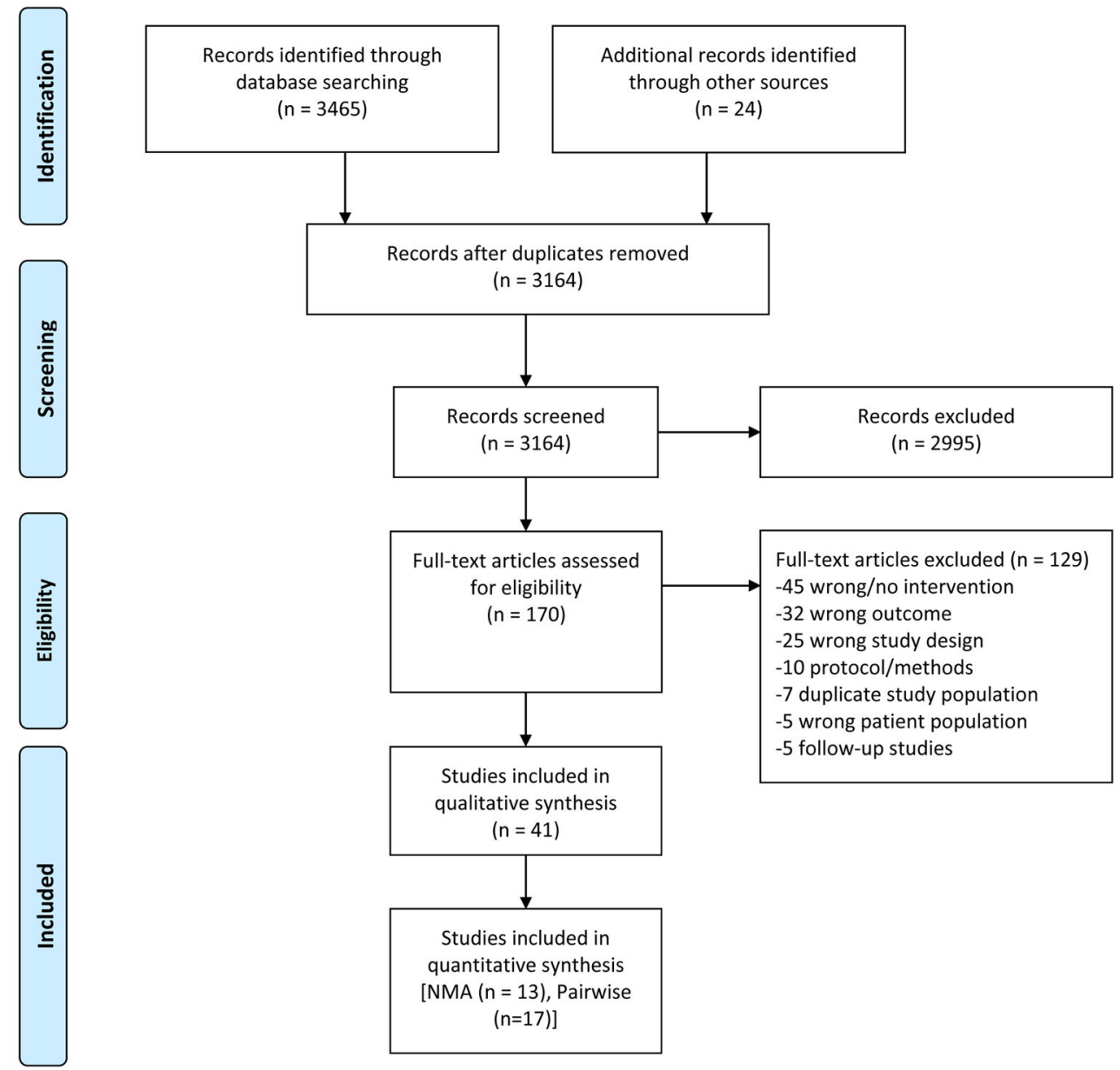

Figure 1.

PRISMA flow diagram of systematic search and included studies. 

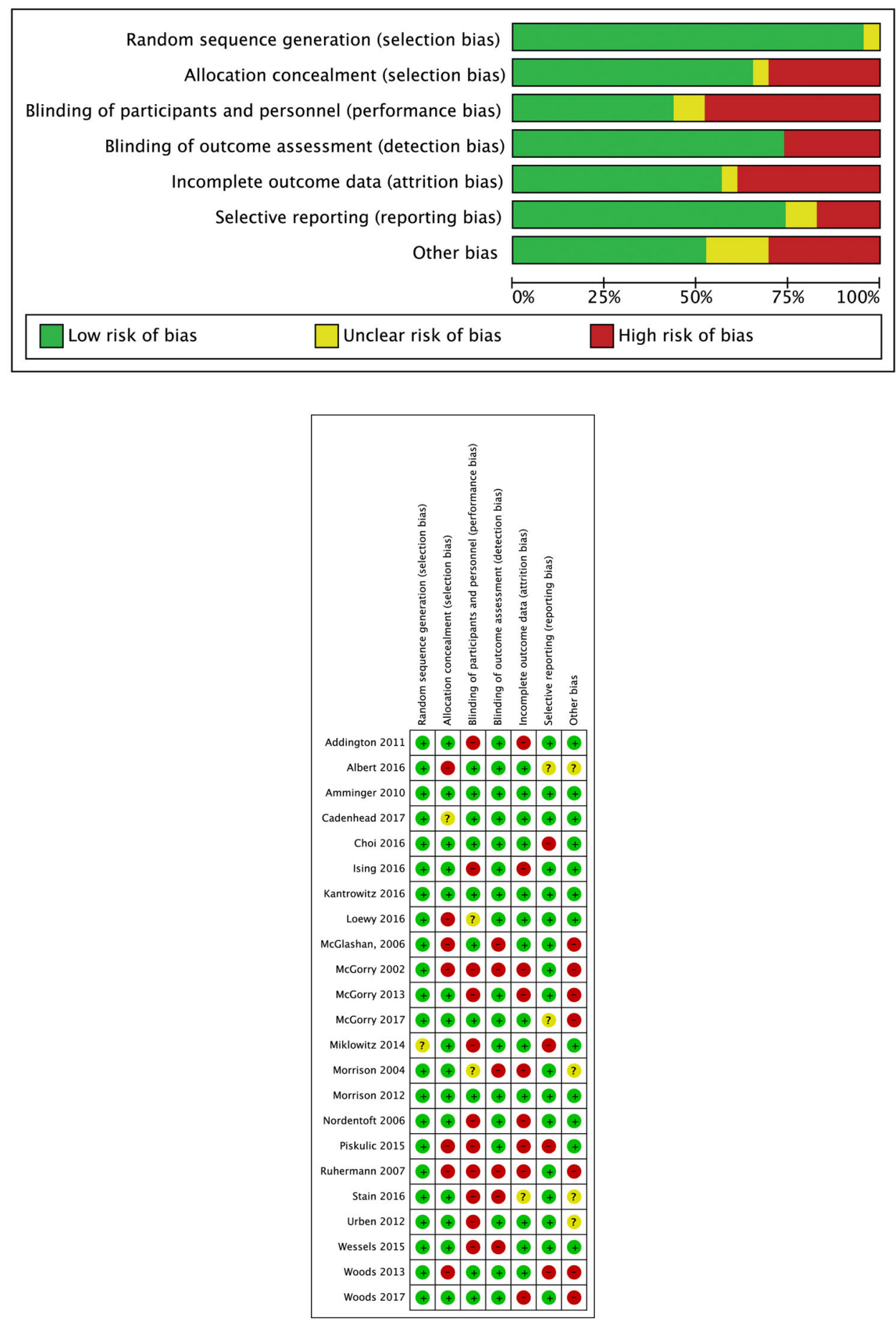

Figure 2.

Early Interv Psychiatry. Author manuscript; available in PMC 2020 February 01. 

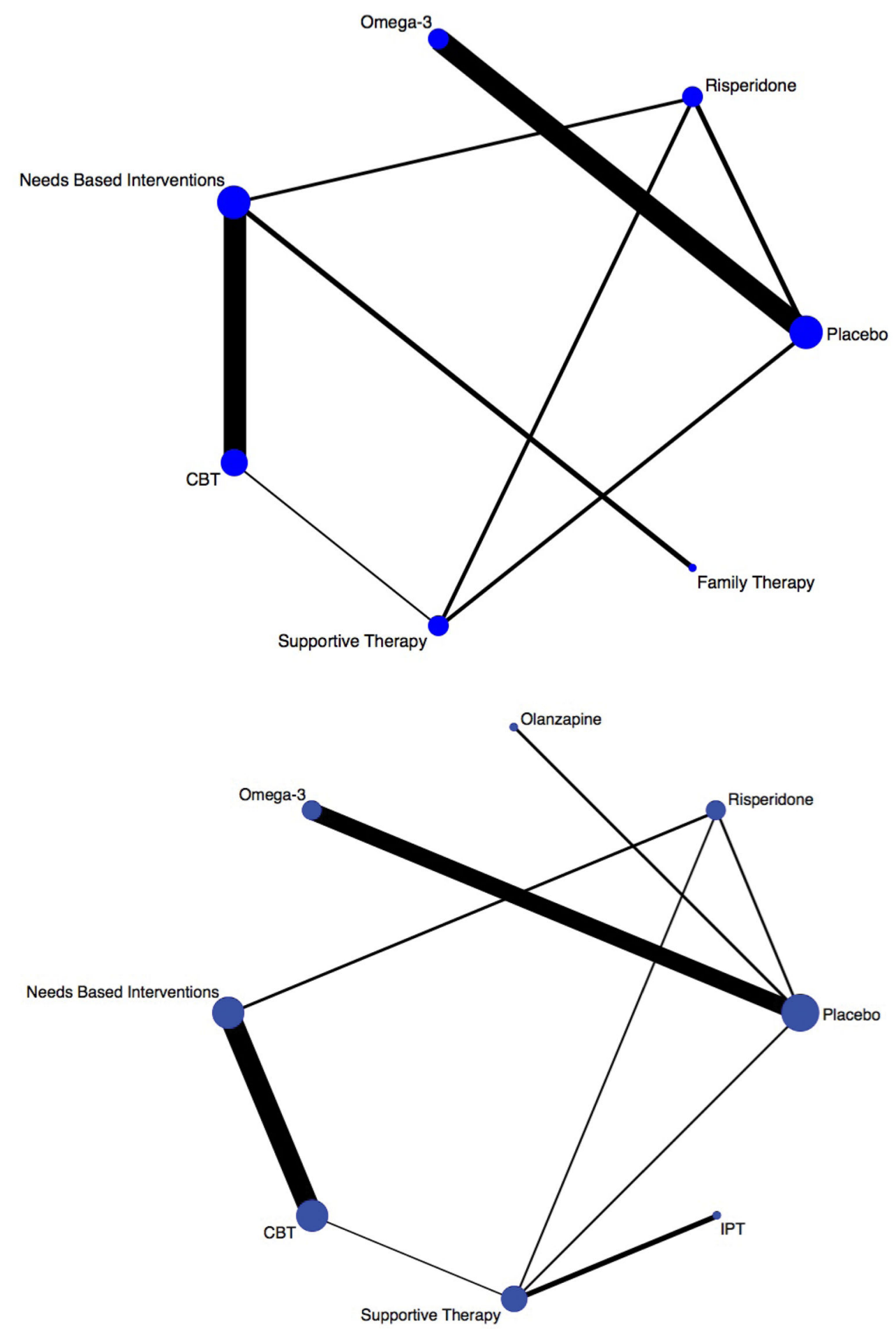

Figure 3.

Early Interv Psychiatry. Author manuscript; available in PMC 2020 February 01. 


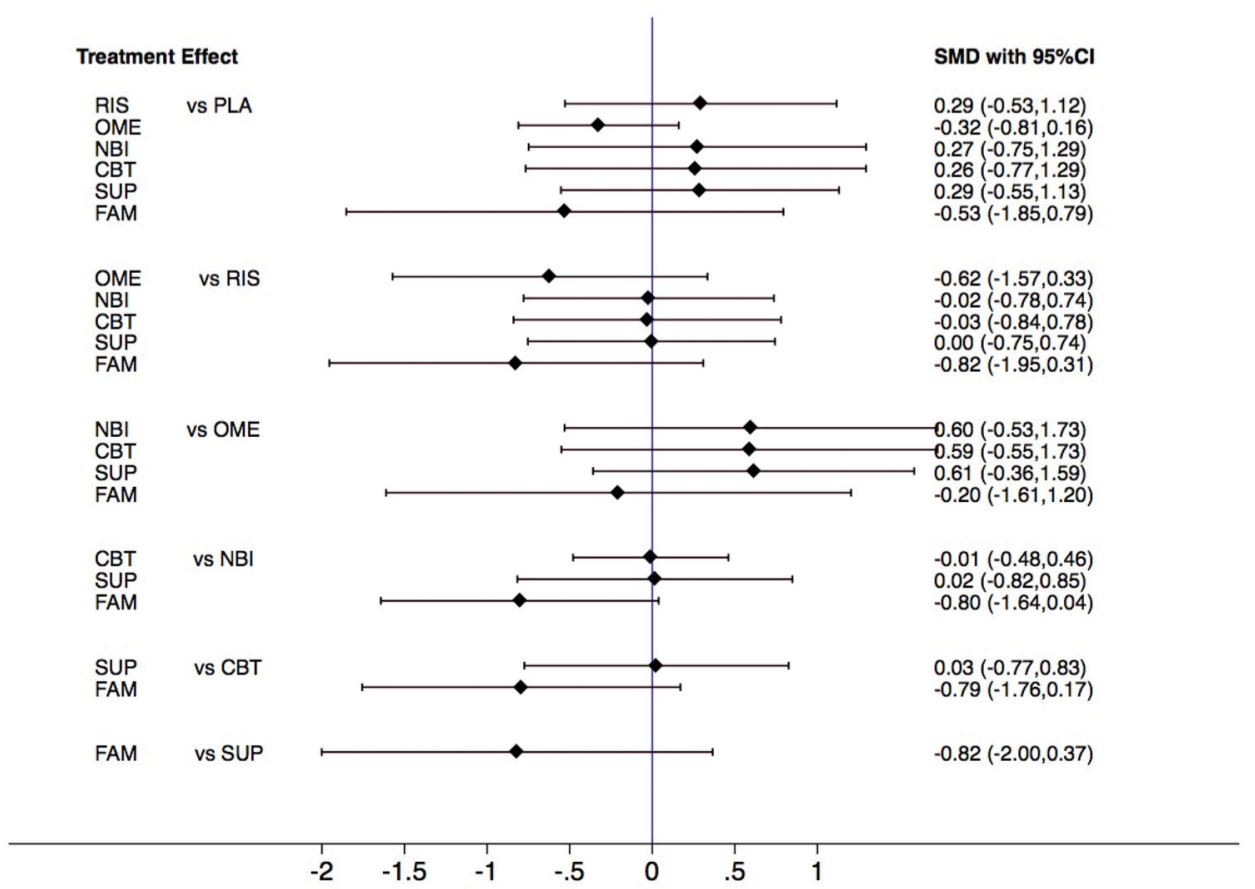

Treatment Effect

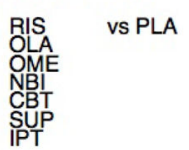

OLA vs RIS

NBI
SUT
IPT

OME vs OLA

NB!
CBT
SUP
IPT

NB! vs OME

IPT

ÇBT
SUPT

SPP IP

IPT vs SUP

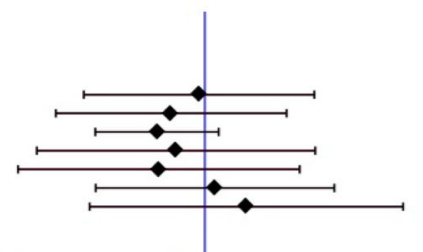

SMD with $95 \% \mathrm{Cl}$

-0.04
$-0.21(-0.75,0.68)$
$-0.93,0.51)$
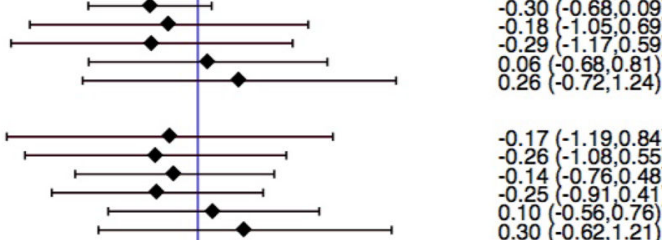

$\left.\begin{array}{l}-0.17(-1.19,0.84 \\ -0.26 \\ -1.08,0.55\end{array}\right)$

$-0.14(-0.76,0.48)$ $0.10(-0.56,0.76)$

$-0.09(-0.90,0.73)$ $-0.08(-1.21,1.06)$ $0.27(-0.76,1.31)$

$0.12(-0.83,1.07)$

$0.56(-0.49,1.61)$

$-0.11(-0.44,0.22)$ $0.44(-0.51,1.39)$

$0.55(-0.39,1.48)$

$0.20(-0.44,0.83)$

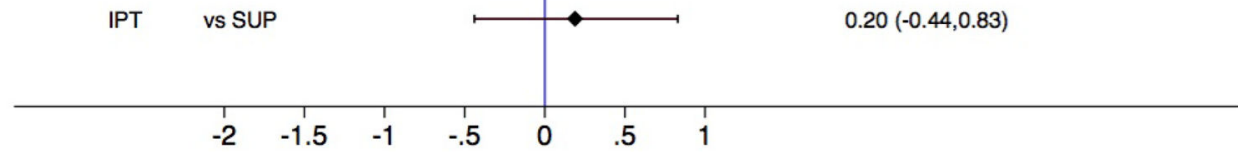

Figure 4.

Early Interv Psychiatry. Author manuscript; available in PMC 2020 February 01. 


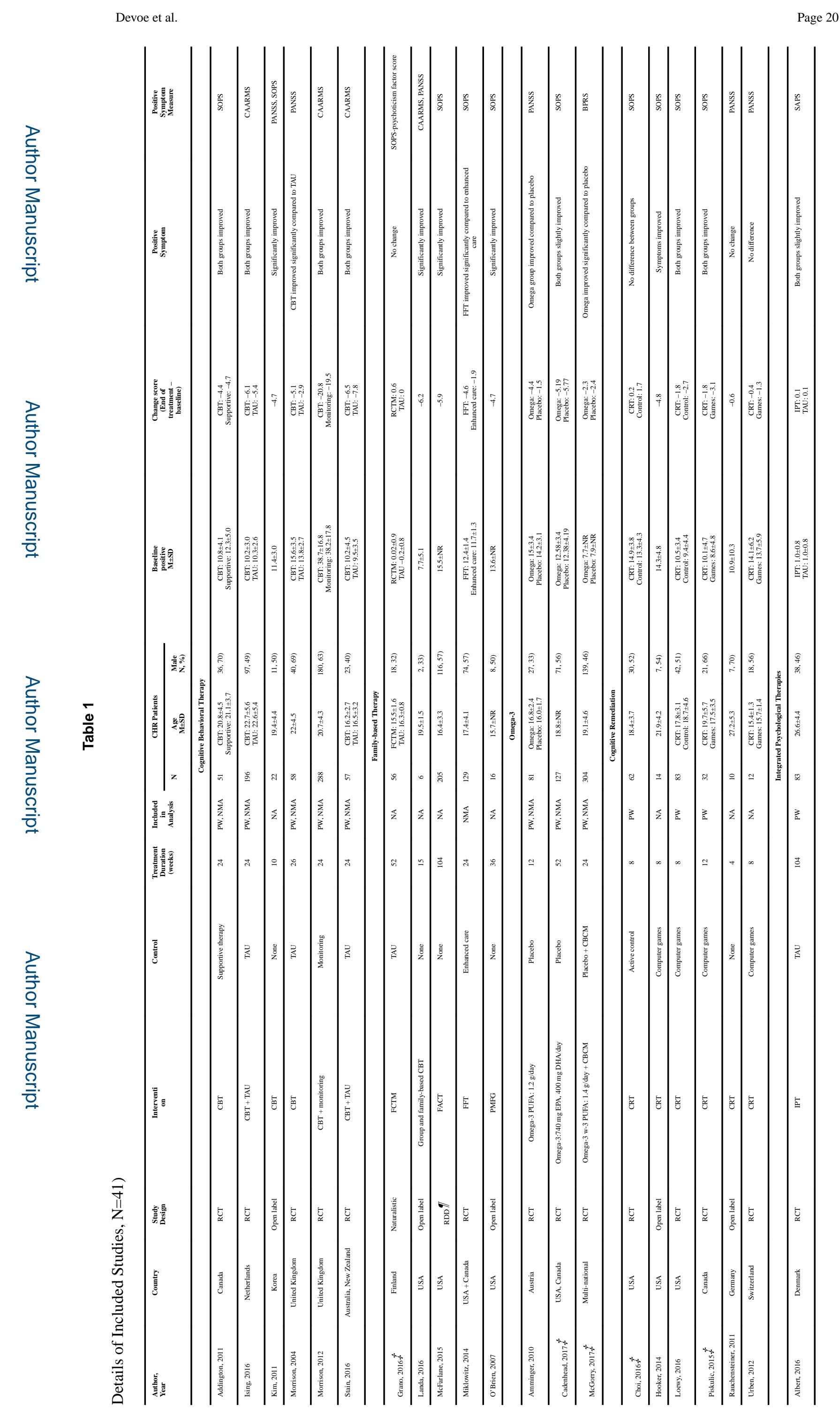



<smiles>C1CCC1</smiles>

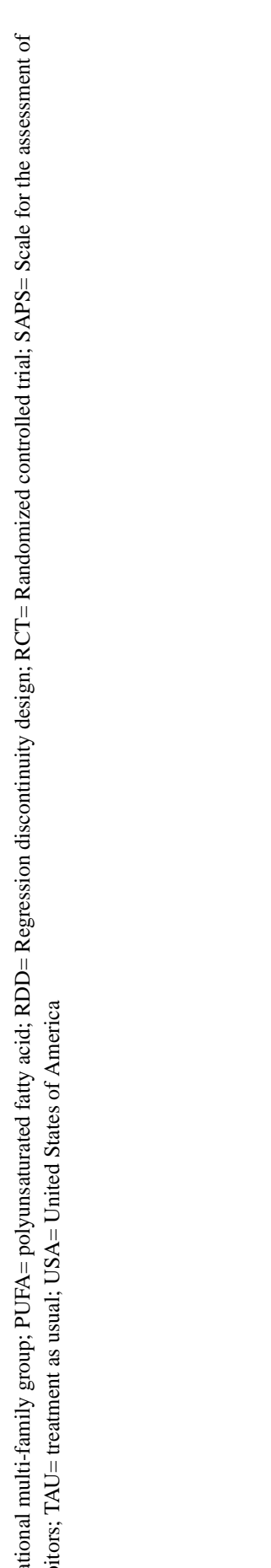

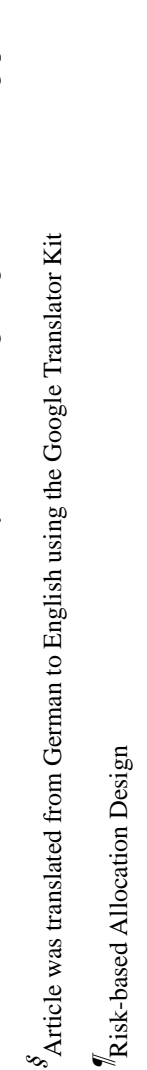

